\title{
Electronic Toll Systems and Their Application for Large Cities
}

\author{
[Petr Kumpošt, Tomáš Padělek]
}

\begin{abstract}
This article deals with implementation of Electronic Fee Collection (EFC) systems in cities. It focuses on division of EFC systems and describes the technology and its advantages and disadvantages. Substantial part is devoted to the description of real application of these systems in large cities around the world and the tendency of these systems being implemented in Czech cities in the context of smart cities concept implementation.
\end{abstract} LPR

Key words - toll system, EFC, DSRC, GNSS/CN, LSVA,

\section{Introduction}

Throughout the world, we can observe the constantly growing intensity of traffic flows and related creation of congestions, which complicate both transportation and our lives, especially in large city centres. One of the possible solutions to these problems is to expand existing and build entirely new roadways, which would increase the capacity of roadway infrastructure and prevent congestion. However, in the compact settings of large cities, this method would be both costly and technically difficult and in many cases would even be unrealistic.

Another option is to apply regulatory and/or organisational measures to prevent drivers from entering certain parts of cities in which the existing intensity of traffic exceeds the capacity of the roadways. One such measure would be collection of tolls within particular zones. In other words, electronic toll systems could be implemented in cities. Several major world cities have already adopted this solution (London, Oslo, Stockholm, Melbourne, Dubai), and others are considering introducing a toll system (Prague).

This article describes the basic characteristics of Electronic Fee Collection (EFC) systems. It focuses on division of EFC systems and describes the technology and its advantages and disadvantages. The second part describes real application of these systems in large cities around the world and the likelihood of these systems being implemented in Czech cities.

\section{EFC systems}

EFC systems are one of the most modern ways of collecting tolls. The total amount to be collected is based on actual roadway use. Users of toll roadways pay fees (tolls)

Ing. Bc. Petr Kumpošt, Ph.D.

Ing. Tomáš Padělek

Faculty of Transportation Sciences, CTU Prague

Czech Republic based on their actual use of areas where tolls have been implemented, rather than tariff-based fees (such as time coupons). Their disadvantage is high initial investment costs compared to time-based fees.

The total amount of fees is most often based on these factors:

- $\quad$ travelled distance;

- $\quad$ vehicle weight and number of axles;

- $\quad$ vehicle emission class;

- $\quad$ time of day (a lower tariff outside of peak periods, etc.);

- location (higher fees in city centres),

- $\quad$ roadway category/class (preference for highways).

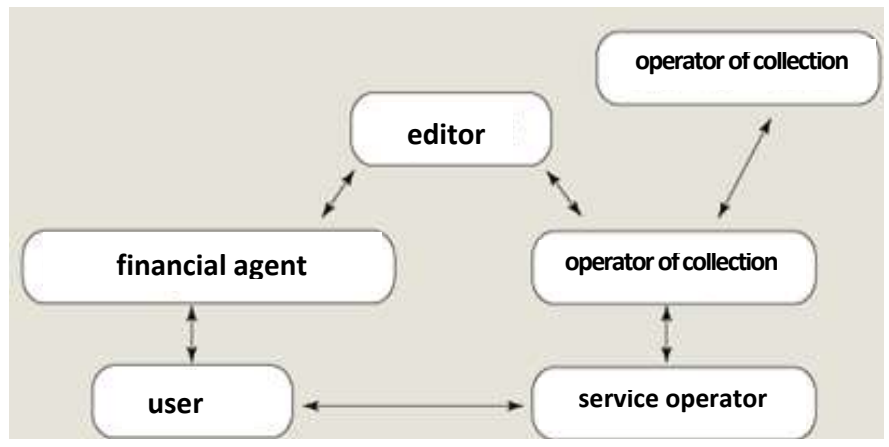

Figure 1 The structure of an EFS system

(http://ekonom.ihned.cz/c1-16137130-gordicky-uzel-kolem-elektronickeho-mytneho)

The method of charging tolls using the EFC system depends on the zone (suburban/urban). In suburban zones, tolls are imposed for vehicles based on the distances travelled on particular roadways (in the Czech Republic highways and selected 1st class roadways). In cities, selection is made within a territory via nationwide monitoring technology upon entrance to the entire charged zone.

EFC systems used in the world can be divided into four groups based on technology.

\section{A. Dedicated Short-range Communication (DSRC)}

This technology uses wireless transmissions over short distances and works based on the principle of microwave and/or infrared transmission of a signal between a vehicle equipped with an On-board Unit (OBU) and Road Safety Equipment (RSE). RSE enables not only collection of tolls, but also detection of non-payers and verification of whether licence plate numbers match the vehicles. The following image illustrates collection of tolls via DSRC. 
Proc. of the Second Intl. Conf. on Advances in Information Processing and Communication Technology - IPCT 2015 Copyright (C) Institute of Research Engineers and Doctors, USA .All rights reserved.

ISBN: 978-1-63248-044-6 doi: 10.15224/ 978-1-63248-044-6-79

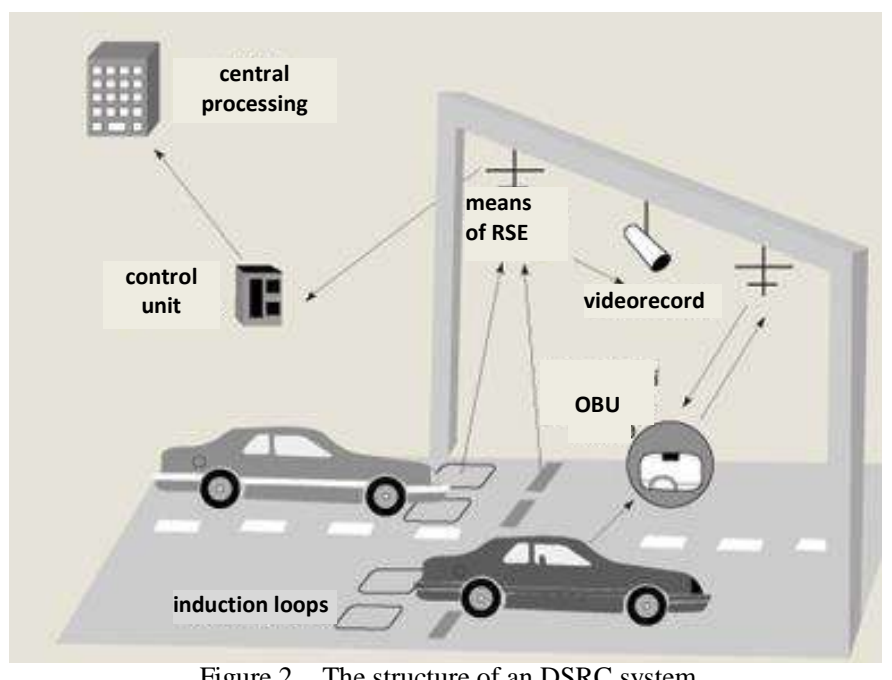

Figure 2 The structure of an DSRC system (http://ekonom.ihned.cz/c1-16137130-gordicky-uzel-kolem-elektronickeho-mytneho)

\section{B. Global Navigation Satellite System /Cellular Network (GNSS/CN)}

This relatively new technology is based on mutual interconnection of two different systems - a global navigation satellite system, which enables capturing of information about a vehicle's position at a given moment in time, and mobile networks (GSM), ensuring communication with a control centre. Unlike DSRC, this technology does not require toll gates to be located near the roadways, but uses what are known as virtual toll points, which can be reconfigured based on needs at different times. Information regarding the specific positions of virtual points is stored in the memory of each OBU located in a vehicle. This technology is not suitable for congested urban areas, since the signal from the satellite could be lost.

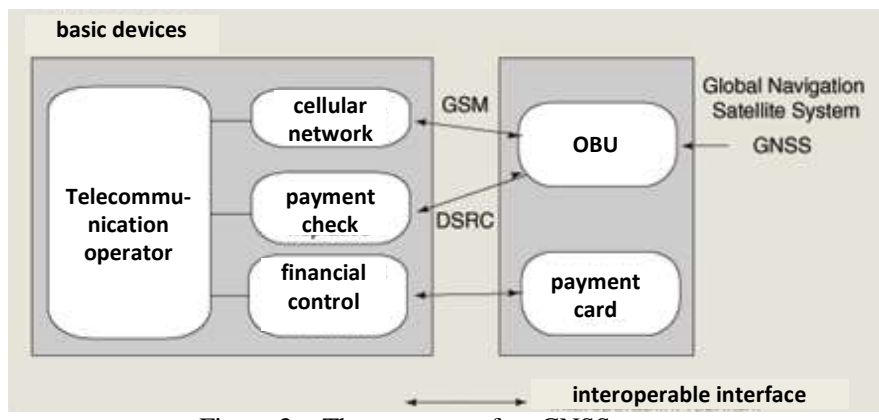

(http://ekonom.ihned.cz/c1-16137130-gordicky-uzel-kolem-elektronickeho-mytneho)

\section{Leistungsabhängige Schwerverkehrs- abgabe (LSVA)}

The LSVA system uses DRSC and GNSS technology in combination with a digital tachograph and is currently installed in locations such as Switzerland. The system is used for detection of vehicles, whose maximum permitted weight is higher than that set. Fee calculation is based on the maximum permitted vehicle weight, the distance travelled and the vehicle emission class. Charges apply for journeys on all roadways, regardless of their categories.
Since this is a closed system, it has been necessary to build up infrastructure for use upon entry and exiting of areas where charges are imposed (in this case on the entire territory of Switzerland). All vehicles registered in Switzerland must be fitted with OBU enabling DSRC communication, GPS signal reception and connection to a digital tachograph. When a vehicle is driven beyond the range of the monitored area, the counter of travelled kilometres in the tachograph is deactivated, and it is reactivated once the driver returns to Switzerland. The OBU is fitted with a chip card that records the current status of travelled kilometres. This card is sent every month to a collection point, where the toll is calculated.

\section{Licence Plate Recognition (LPR)}

Neither OBU nor RSE are required for operating this system. The principle of this technology is based on licence plate recognition using cameras. Special software enables automatic recognition of licence plate numbers from a video recording. This ensures the smooth course of the entire process, without the need for the driver to slow down or stop. The evaluated information from the camera recording is sent to a control centre, where each licence plate number is compared with a database of users who have made payments. If agreement is not found, the licence plate number is entered into a temporary database recording unpaid tolls. If the assessed tolls are not paid by the set deadline, the licence plate will be moved to the database of sanctions. Before the driver enters the zone for which the toll applies, payment can be made via SMS, the internet, a credit card, vending machines, etc.

\section{Use of EFC systems abroad}

\section{A. London, United Kingdom}

Tolls were introduced in London on $17^{\text {th }}$ February 2003. Until that date, tolls were charged only in a small part of the city centre near large businesses and government offices. The zone currently covers the entire historic city centre, the financial quarter and the West End quarter, which is the primary commercial and entertainment centre of London, and the zone in the western part of the city was expanded later. That expansion was subsequently reversed, and therefore tolls applied for the area only between 2007 and 2011. At the time of introduction of the tolls, the number of public transport buses was increased, with approximately 300 connections added (out of a total of 8,000 ), and the routes of lines were further changed based on expected demand. Approximately 183,000 inhabitants live in the area where the toll applies, but it is estimated that around a million people commute to the zone for work. 


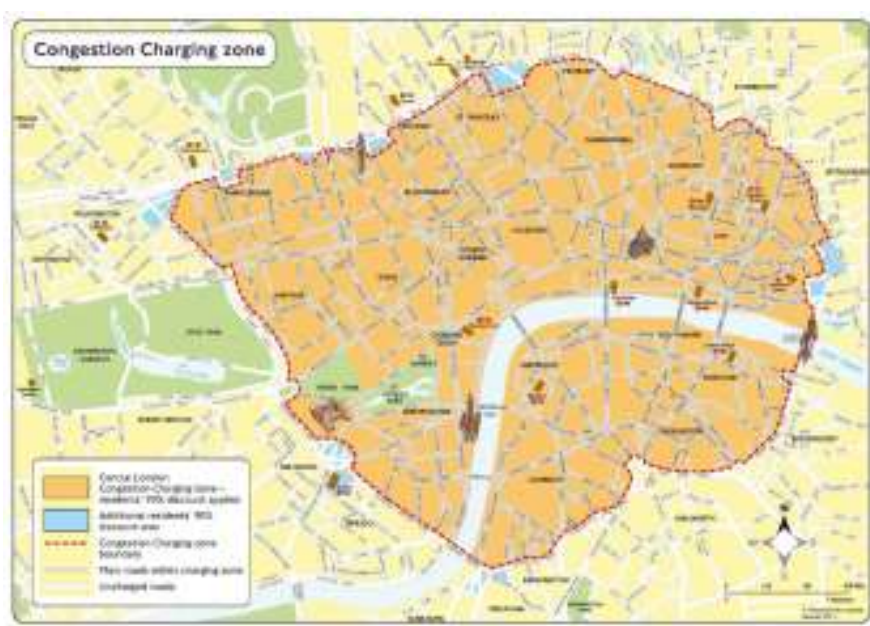

Figure 4 The toll zone in London (3)

(http://www.tfl.gov.uk/cdn/static/cms/documents/congestion-charge-zone-map.pdf)

A toll is imposed on vehicles travelling to the charged zone between 7 a.m. and 6 p.m. Monday through Friday. Tolls do not apply on weekends, state holidays or between Christmas Eve and New Year's Day. The daily fee is GBP 11.5 (GBP $1=$ CZK 35.2), and the easiest way to pay is via the internet. Tolls can also be paid at approved shops, via automatic terminals, via SMS or via a call centre. Costs can be reduced by GBP 1 per day when using the CC Auto Pay system. Several discounts also apply for certain types of vehicles, depending on, for example, $\mathrm{CO}_{2}$ emissions, the number of seats, the purpose for use of the vehicle, the vehicle owner's residential address, etc.

After the toll system was implemented, the number of vehicles entering the charged zone decreased by $16 \%$ (according to data from 2006). This led to a reduction of delays, there was also a positive effect from more eco-friendly vehicles, and reduction of concentrations of harmful substances in the atmosphere was detected, such as a $20 \%$ drop in CO2 emissions. However, there has been much debate about how much of an effect on improving air quality the introduction of tolls has, and experts believe that it is not possible to determine exactly how much such improvements can be attributed to these types of measures.

\section{B. Sydney, Australia}

This is Australia's largest city, and there is traffic congestion throughout it. A significant amount of the congestion in Sydney can be attributed to lorry traffic, because most freight is transported from ports through cities via lorries.

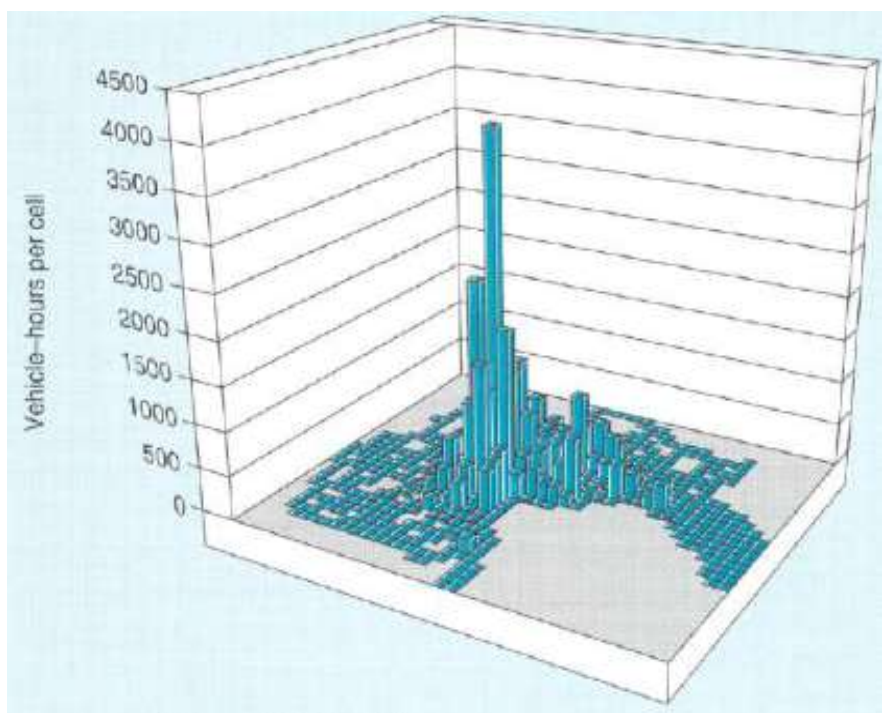

Source BTCE modelling results.

Figure 5 The delay in peak hours in Sydney (3)

Total traffic is expected to increase $40 \%$ by 2020 compared to its current volume. The likely share of roadway traffic, which will obviously be dominant, remains a question.

Individual Australian states are attempting to include methods and approaches in their plans for reducing congestion, with the help of better and higher quality mass transport and promotion of cycling and walking.

Sydney has its own development plan titled "Future Sydney, a City of Cities" which also includes a traffic and transport strategy (with an outlook of 25 years). The plan also includes measures to reduce congestion, such as investments into expansion and improving the quality of rail, bus and existing roadway infrastructure, improving the effectiveness of freight transport and influencing the selection of individual types of transport.

\section{Use of EFC systems in the Czech Republic}

There are currently no toll systems in any cities in the Czech Republic. This is true even despite increasing traffic and problems such as congestion, pollution, parking problems, etc. However, studies have been conducted in cities such as Prague and Ostrava, which are intended to find optimum solutions to these problems.

Two studies were conducted in Ostrava in 2011, which were intended to combat the negative effects of motor vehicle traffic on air quality in Ostrava. One has the name "Closing Wider Areas of the Centre of Ostrava for Motor Vehicle Transport as Part of Anti-smog Measures" and the other is named "Evaluation of Options for Implementing Low-emission Zones in the Statutory City of Ostrava". However, neither of these proposed solutions has yet been applied, since the studies found that it is very difficult to determine where the pollution comes from and how much of it can be attributed to vehicle traffic. Therefore, 
Proc. of the Second Intl. Conf. on Advances in Information Processing and Communication Technology - IPCT 2015

Copyright $(\odot$ Institute of Research Engineers and Doctors, USA .All rights reserved.

ISBN: 978-1-63248-044-6 doi: 10.15224/ 978-1-63248-044-6-79

the city resorted to a solution involving an increase in the attractiveness of urban and suburban mass transport.

The introduction of tolls has been considered in Prague for a relatively long time, and a study has also been conducted there regarding its potential effectiveness. The study found that if tolls were introduced in 2015, it would cost CZK 640 million to put the system into operation, and each driver would pay CZK 120 to enter toll zones. This solution has now been postponed, mainly because tolls cannot be collected in the city without a change of legislation, and the city is waiting for the completion of construction of the city bypass and internal ring road, so that drivers would have an alternative route.

It is apparent from the already carried out application of tolls in cities that they not only can achieve reduction of the number of cars in use and reduction of congestion and emissions caused by their use, but can lead to a lot of cost savings as well. In view of the specifics of each city, it is always important to decide which of the systems should be selected. Communication with inhabitants is also very important, so that the reasons for introducing tolls are explained to them properly. Collected tolls can be reinvested into restoration of traffic and transport infrastructure, improving the quality of public transport (which should serve as the main means of transport in cities) and environmental restoration.

Experience from already implemented toll systems on highways in the Czech Republic (1),2) can also be used.

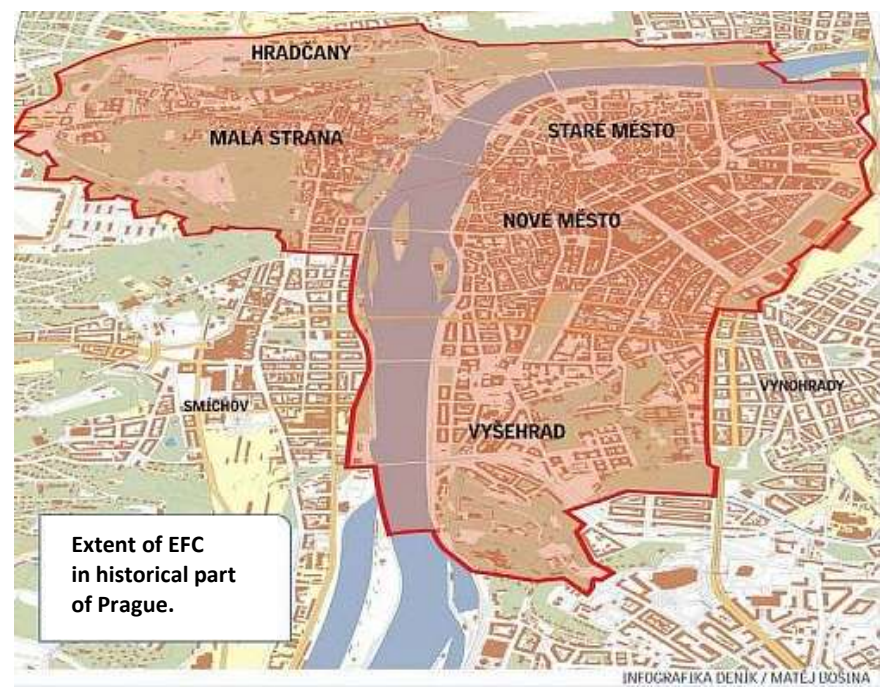

Figure 6 The idea of the toll zone in Prague (3)

\section{v. Comparison of EFC systems}

In order to select a suitable EFC system, it is necessary to compare their advantages and disadvantages (see Table 1). When selecting specific technology, investment demand and technological reliability always play the main role. It will also be beneficial to conduct an analysis of types

of technology already used in particular territories or countries, so that systems can be interconnected. This will increase user comfort and lead to more use of the system.

Table 1 The Comparison of EFC Systems

\begin{tabular}{|l|l|l|}
\hline & \multicolumn{1}{|c|}{ Advantages } & \multicolumn{1}{c|}{ Disadvantages } \\
\hline DSRC & $\begin{array}{l}\text { cheap OBU devices } \\
\text { easy installation of OBU } \\
\text { suitable for passenger cars } \\
\text { well-tried technology } \\
\text { standardization } \\
\text { oversight of defaulters }\end{array}$ & $\begin{array}{l}\text { expensive infrastructure } \\
\text { coverage of selected road only } \\
\text { detour routes risks } \\
\text { incompatible system } \\
\text { vulnerable system }\end{array}$ \\
\hline GNSS/CN & $\begin{array}{l}\text { entire network coverage } \\
\text { flexibility } \\
\text { EU support } \\
\text { elimination of detour routes } \\
\text { robust system } \\
\text { motorists services improvement }\end{array}$ & $\begin{array}{l}\text { expensive OBU devices } \\
\text { technology with bugs } \\
\text { no standardization } \\
\text { difficult oversight of defaulters }\end{array}$ \\
\hline LSVA & $\begin{array}{l}\text { entire network coverage } \\
\text { elimination of detour routes } \\
\text { well thought-out system } \\
\text { interoperability with DRSC }\end{array}$ & $\begin{array}{l}\text { expensive OBU devices } \\
\text { difficult installation of OBU } \\
\text { no standartization } \\
\text { digital tachograph required } \\
\text { border infrastructure required }\end{array}$ \\
\hline LPR & $\begin{array}{l}\text { does not use OBU } \\
\text { suitable for passenger cars } \\
\text { cheap system }\end{array}$ & $\begin{array}{l}\text { suitable as EFC system only } \\
\text { incompatible system } \\
\text { for closed areas only }\end{array}$ \\
\hline In view & of the constantly deve & oping satellite navigation
\end{tabular}

In view of the constantly developing satellite navigation technology, including related services, the use of the GNSS/CN system would probably have the most advantages in large cities and their immediate surroundings. Particularly in historic city centres (such as in Prague), building necessary infrastructure would be very demanding. A disadvantage to a certain extent could be the loss of the signal when transiting through an area with tall structures. However, reliability in this respect should be ensured by the already mentioned combination of satellite navigation and a protocol for mobile phones.

\section{Refferences}

[1] L. Bína, V. Černý, H. Nováková; "Road Charging in the Czech Republic and EU and External Costs of Transport"; Journal of Civil Engineering and Architecture; ISSN 1934-7359; USA; vol. 6, no. 12 (serial no. 61), pp. 1672-1678; 2012

[2] L. Bína, H. Nováková, M. Jánešová; "ITS and Electronic Toll Systems"; Transactions on Transport Sciences; ISSN 1802-9876 (online) ISSN 1802-971X (print),); Czech Republic; vol. 5, no. 3, pp. 151-168; 2012

[3] OECD International Transport Forum; "Řízení městských dopravních kongescí”; ISBN 978-80-86502-96-0; Czech Republic, CDV Brno; pp. $\quad 89 ; \quad 2011 ; \quad$ online http://www.internationtransportforum.org /Pub/pdf/09CongestionCZ.pdf

\section{Acknowledgement}

The authors acknowledges support from the project Title: The operational programme Prague Adaptability Development of the master's study programme N 3710 - "Technology and Technics of Transport and Communications "in the introduction of teaching of the concept „Smart cities“, CZ.2.17/3.1.00/36035.
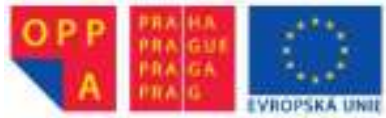

Evropský sociálni fond

Praha \& EU: Investujeme do vaśi budoucnosti 